International Journal of Engineering \& Technology, $7(3.1)(2018)$ 136-138
International Journal of Engineering \& Technology
SPC
Website: www.sciencepubco.com/index.php/IJET
Research paper

\title{
E-Learning Concepts, Merits and Demerits
}

\author{
R Valarmady ${ }^{1}$, D Pradeepa ${ }^{2} *$, S G Rajasekar ${ }^{3}$ \\ ${ }^{1}$ Librarian, Jeppiaar Engineering College, Chennai. \\ ${ }^{2}$ Assistant Librarian, Jeppiaar Engineering College, Chennai. \\ ${ }^{3}$ Academic Officer, Sri Venkateswara College of Engineering, Chennai. \\ *Corresponding author E-mail:deepavenkat8@gmail.com
}

\begin{abstract}
This research work scrutinizes the helpfulness of utilizing e-learning in training in tertiary organizations. In concerns of better learning, the apprehension of using modern facts and communiqué equipments for training and intellect is tremendously essential. This investigation evaluates prose and provides an insightful foundation to the examination by reviewing a few obligations finished by different investigators and establishments on the idea of e-learning, especially its tradition in training and knowledge in superior learning organizations. It reveals a few sights that public and organizations have communal every comprehensive on the misappropriation and incorporation of e-learning schemes in teaching during reviews and some other surveillances.
\end{abstract}

Keywords: E-Learning, System Architecture, Merits and Demerits.

\section{Introduction}

Whilst the word "e-learning" has been tossed around rather a great deal in current years, numerous are as yet ignorant of what it really means and how it tin assist them attain achievement in both their expert and individual survives. This petite e-book intends to offer an initial stage impression of the e-learning meadow for those public. This e-book is separated into five principle themes. The main theme locates the box for e-learning by trade with topics, for exemplar, its narration, its benefits and any drawbacks, and whether it tin actually guide to learning. The next theme illustrates serious forms of learning tools that are obtainable nowadays. The third theme contracts with the traits of online tracks and how solitary tin make victorious learning areas. The fourth theme is joined in with budding learning drifts. At this point we clarify premises, for exemplar, miniaturized level learning and gamification. What's extra, the most recent theme illustrates the exploitation of elearning in dissimilar productions.

When it approaches to edification, the replica has been attractive directly onward - up pending the premature ' 00 s edification was in a classroom of scholars with an educator who lead the procedure. Corporeal occurrence was an effortless verdict, and a few other form of learning was debatable, finest crate set-up. Then the workstation fruition occurred and it radically altered the learning scenery. In spirit, e-learning is a workstation depends edifying mechanism or scheme that permits you to study wherever and whenever you like. Nowadays e-learning is normally distributed though the internet, in spite of the truth that in the history it was distributed exploiting a unify of workstation depends process similar to CDROM.

Knowledge has superior so great that the environmental gap is conduit with utilize of apparatuses that create you sense as although you are within the group of students. E-learning proffers the ability to divide substance in a broad choice of associations, for instance, records, slideshows, word files and PDFs. Foremost webinars (live online classes) and talking with lecturers by re- sources of stay and note conversations is furthermore an substitute accessible to customers. There is a surfeit of dissimilar e-learning schemes (or else called as Learning Management Systems, or LMSs for tiny) and techniques, which get keen on description routes to be conveyed. Through the exact tool dissimilar procedures may be computerized, for instance, the scrutiny of checks or the formation of appealing comfortable. E-learning gives the students with the ability to well knowledge about their existences, successfully allowing still the busiest one to extra a livelihood and enlarge innovative facilities.

Few of majority critical improvements in learning contain occurred as the transmit of the internet. At the time students are fine rhymed in the utilize of stylish handsets, content messaging, utilizing the internet thus enchanting an attention in and consecutively an online lessons have befall a easy illicit relationship. Significance pieces, web-based societal networking, different new signifies of online correspondence enable students to remain in contact and talk about lesson allied issues, while accommodating an intellect of system. In the quick licked universe of e-learning the obtainable technologies to create lessons exhilarating are frequently altering, and lessons substance may and ought to be modernized rapidly to provide students the extremely newest data. It is specially vital but the e-learning preparing is creature specified to people in a region where maintenance a la mode on commerce improvements is absolutely critical. It is the motivations why numerous dealings are currently present preparing by means of e-learning further causes embraces little expenses and also the capacity for workers to think about time permitting and leave. Generally, conventional knowledge is luxurious, gets quite a while and the consequences may fluctuate. E-learning proffers a substitute to be earlier, economical and possibly superior.

The word "e-learning" have now been in survival as 1999, while the utterance is original exploit at a CBT schemes tutorial. Extra terms likewise begin to bind up and about in hunt of a precise portrayal, for instance, "online learning" and "virtual learning". On the other hand, the standards at the back e-learning enclose be fine recognized throughout the past, and here is still proof which pro- 
poses that untimely types of e-learning survived as distant rear as the nineteenth century.

\section{E-Learning System Architecture}

The fundamental prerequisite of the extenders whilst enlarging every e-learning scheme is to it ought to choose simple to utilize and secure. Learners ought to survive clever to decide their lessons, learn the possessions simply, remain tabs on their development, attain their last objective on moment [1]. In the education scheme learners ought to survive clever to converse and assist all together, otherwise it ought to survive communal and appealing. Whilst budding the knowledge scheme the trendy ought to centre on making a great unify of habitual and effective learning techniques to assist the learners connect extra and attain their objectives [2].

A great e-learning scheme is unify of learning schemes emerged in figure 1. In speculation the great e-learning scheme can facilitate learners to study as of from house as containing a few immediate prop up and communication with some other learners who are captivating the equivalent lessons though it can be stiff to realize in genuine crates.

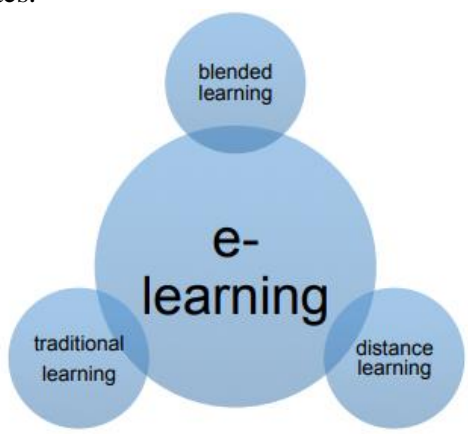

Fig. 1: Learning Models

The structural design of an e-learning scheme may be hard to understand in scientific phrase yet it for the most part comprises of 3 sections:

- User Interface

- Platform

- Database.

A database is the lay wherever the computerized knowledge resources are stockpiled and a knowledge phase is the medium as of which the learners entrée the knowledge resources. A client boundary is the obsession that the learner observes whilst contacting the phases. The correspondence procedure among the $3 \mathrm{seg}$ ments is extremely necessary for the entire scheme to effort perfectly. For instance, we may utilize MySQL to hoard the computerized substances, utilize edX phase to admittance the substances and learners may stay the edX stage utilizing their trap browser.

The association among the 3 sections of the e-learning scheme is appeared in figure 2 .

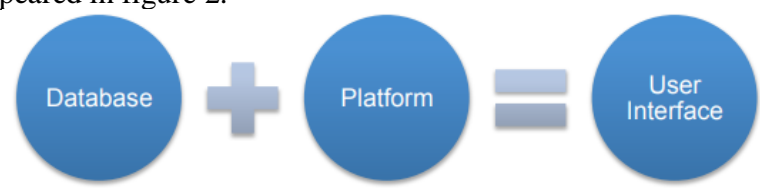

Fig. 2: Connection between parts of learning system

As should be obvious from the figure 2, the user interface is the obsession that the learner observes whilst contacting the phase, which resolve contain the contact to the folder. The user interface is denoting by which the learner interrelates with the scheme, counting the information tools and the software. It enables consumer to include their order during information tools, for instance, a mouse or phone display and demonstrates the consequences of the consumer effort. Relevance's and web browsers are a few instances of the user interfaces. A database is a prearranged situates of information or data prearranged with the objective that it may be contacted, directed and efficient at any time essential. In sort to hoard, alter, extort and oversee the file an administration scheme, database management system (DBMS) is requisite. There are several DBMS accessible in the bazaar similar to Oracle, Microsoft SQL Server, and MySQL [3].

The e-learning phase is the scheme that offers the admittance to the folders of e-learning substances or the online lessons. The stages are normally web-based. It facilitates the consumer to admittance the assessment substances, get checks, and remain tags on their development every time or everywhere they need. There are numerous such stages accessible in market. Corporations may also utilize such stages or enlarge their hold. Enlarging such stages might be exclusive, thus corporations normally utilize previously offered stages. The stages could be gratis or profitable. The marketable stages resolve the corporations to modify them to robust requires of the consumers. Whilst picking the stage it is essential for the corporations to appreciate what they necessitate. It based on a quantity of rudiments, for instance, requires of learners and technological abilities of educators [4].

\section{Merits and Demerits of E-learning in Higher Education}

\subsection{Merits}

The selection of E-learning in teaching, particularly for advanced enlightening practicalities has numerous advantages, and specified its numerous improvements and advantages; e-learning is measured between the finest techniques of instruction [5]. Numerous learns and creators encompass offered advantages and benefits resultant from the reception of e-learning equipments into educates. A few learns provide benefit of e-learning since its capacity to centre requires of personality students. A few of the benefits that the choice of e-learning in teaching, attained as of appraisal of prose contains the supplementary:

1. It is supple while concerns of occasion and position are full keen on deliberation. All learners have the advantage of picking the position and occasion that costumes him/her. The reception of e-learning offers the establishments and in addition their learners or students the greatly litheness of occasion and position of liberation or delivery of as integrated by education information [6].

2. E-learning increases the efficiency of information and potential by way of easiness of admittance to a enormous gauge of data.

3. It can offer chances for relatives among students by utilize of discussion crowds. Throughout this, e-learning assists eradicate a fence that has the probable of deterring assistance with the dread of discussing with new students. E-learning encourages learners to interrelate by each other, also replace and reverence dissimilar reason of sights. E-learning easiness communication in addition advances the rapports that maintain knowledge. E-Learning creates obtainable spare scenes for interactivity among learners and educators among pleased liberation [7].

4. E-learning is financially savvy in the intelligence to present is nix require for the learners or students to voyage. It is furthermore savvy in the intellect that it tenders chances for knowledge for most great figure of students by no require for a few makeups.

5. E-learning dependably gets keen on reflection the personage student's distinctions. A few students, for example favour to ponder on sure pieces of the lessons, whilst furthers are equipped to appraisal the whole lessons.

6. E-learning assists recompense for shortages of educational team, with teachers or educators as well catalysts, lab technicians etc.

7. The exploit of e-Learning permits nature-licking. For example the offbeat method allows all learners to study at his/her possess lick and rate whether reasonable or quick.

The aforesaid benefits of e-learning have been calculated awake by captivating memorandum of that the ability of e-learning to levy the learners or students as they study, at the similar occasion growing their knowledge's in teaching, by technique for interac- 
tivity fit to system learning, communal variety, globalization, and destroying limits of lay and occasion. To them the mainly indispensable traits and additionally advantage of e-learning in education is that it centres on the students or learners [8].

\subsection{Demerits}

E-learning, in spite of the advantages that it has when adopted in education, additionally has some demerits. Studies bolster that e-learning possesses some disadvantages. The demerits of e-learning that have been given by studies include the accompanying:

1. E-learning as a method of education makes the learners undergo contemplation, remoteness, and in addition absence of interaction or relation. It therefore requires a very solid motivation and additionally aptitudes with to the management of time in order to reduce such effects.

2. With respect to illuminations, offer of explanations, and also interpretations, the e-learning method may be less effective that the customary method of learning. The learning process is significantly easier with the use of the face to face encounter with the educators or teachers.

3. When it comes to improvement in relational abilities of learners, e-learning as a method may have a negative effect. In spite of the fact that may have an excellent knowledge in academics, they may not possess the needed aptitudes to deliver their acquired knowledge to others.

4. Since tests for assessments in e-learning are perhaps done with the use of intermediary, it will be troublesome, if not impossible to control or regulate terrible activities like cheating.

5. E-learning may likewise most likely be misled to robbery and copyright infringement, predisposed by inadequate selection abilities, and also the ease of reorder.

6. E-learning may likewise deteriorate establishments' role socialization role and furthermore the role of teachers as the directors of the process of education.

7. Likewise not all fields or discipline can employ the elearning technique in education. For instance the purely scientific fields that include commonsense can't be properly studies through e-learning. Researchers have argued that e-learning is more appropriate in sociology and humanities than the fields, for example, medical science and drug store, where there is the need to develop down to earth aptitudes.

8. E-learning may likewise lead to congestion or heavy use of some websites. This may realize unanticipated costs both in time and money disadvantages.

\section{Conclusion}

E-learning involves the use of computerized instruments for teaching and learning. It makes use of technological instruments to enable learners consider anytime and anywhere. It involves the preparation, delivery of knowledge and motivates students to interact with each other, and in addition exchange and respect different purpose of views. It eases correspondence and improves the relationships that manage learning. Despite some challenges discussed, the literature has tried to explain the role of e-learning specifically and how e-learning has made a solid effect in teaching and learning. Its reception in some organizations has increased workforce and learner's access to data and has provided a rich environment for joint effort among students which have improved academic guidelines. The overall literature which explains the merits and demerits of e-learning suggests the need for its implementation in higher education for workforce, managers and students to enjoy the full benefits that come with its reception and implementation.

\section{References}

[1] Nischal Guragain, E-Learning Benefits and Applications, Helsinki Metropolia University of Applied Sciences, (2016).

[2] El-Ghareeb H A., "E-Learning and Management Information Systems", ELearn Magazine, (2009).

[3] Stroud F. ServerWatch, "Top 10 Enterprise Database Systems to Consider in 2017", (2017).

[4] Christian Dalsgaard, "E-learning beyond learning management systems", Social software, (2016)

[5] Valentina Arkorful, Nelly Abaidoo, "The role of e-learning, the advantages and disadvantages of its adoption in Higher Education", International Journal of Education and Research, Vol. 2 No. 12, (2014), pp.397-410.

[6] Smedley, J.K., "Modelling the impact of knowledge management using technology", OR Insight, (2010) 23, pp.233-250.

[7] Wagner, N., Hassanein, K. \& Head, M., "Who is responsible for Elearning in Higher Education? A Stakeholders", Analysis. Educational Technology \& Society, 11 (3), (2008), pp.26-36.

[8] Holmes, B. \& Gardner, J. (2006). E-Learning: Concepts and Practice, London: SAGE Publications. 